\title{
Short and Modular Synthesis of Substituted 2-Aminopyrroles
}

\author{
Raquel Diana-Rivero, Beate Halsvik," Fernando García Tellado,* and David Tejedor*
}

Cite This: Org. Lett. 2021, 23, 4078-4082

Read Online

ACCESS I

山ll Metrics \& More

| 回 Article Recommendations

Supporting Information

ABSTRACT: We herein describe a simple and metal-free domino methodology to synthesize 2-aminopyrroles from alkynyl vinyl hydrazides. The domino reaction involves a novel propargylic 3,4diaza-Cope rearrangement and a tandem isomerization/5-exo-dig $\mathrm{N}$ cyclization reaction. By using this approach, a number of 2-aminopyrroles with diverse substituents have been prepared.
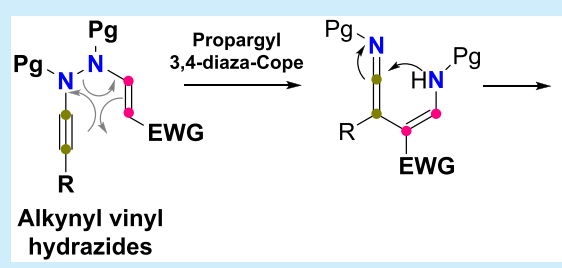

EWG

hydrazides

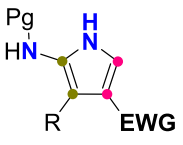

Monoprotected 2-aminopyrroles
$\mathrm{T}$ he 2-aminopyrrole ring constitutes an architectural motif present in many bioactive compounds spanning a wide set of pharmacological activities. ${ }^{1}$ Selected examples include multisubstituted pyrroles I and II, which are inhibitors of mitogen-activated protein kinase enzymes (MEKs) ${ }^{1 \mathrm{a}}$ and metallo- $\beta$-lactamases (MBL), ${ }^{1 \mathrm{~b}}$ respectively, or the heterofused pyrrole III, a modulator of B-cell lymphoma 2 (Bcl-2) family members $^{1 \mathrm{c}}$ (Figure 1). Besides these therapeutic applications, 2 -aminopyrroles have found use as molecular platforms in the synthesis of analogues of purine bases. ${ }^{2}$

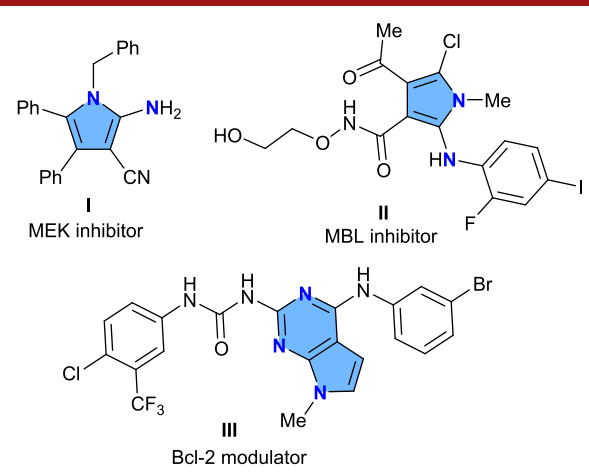

Figure 1. Bioactive 2-aminopyrroles.

These properties are made of these 5-membered heterocycle recurrent synthetic targets. ${ }^{3}$ Although the synthesis of pyrroles is well established and a good number of efficient methodologies based on the classical Knorr, ${ }^{4}$ Paal-Knorr, ${ }^{5}$ and Hantzsch $^{6}$ reactions are already available, ${ }^{7}$ they are not easily adapted to the synthesis of 2-aminopyrroles. These limitations have fueled the development of novel synthetic strategies to gain access to these substituted pyrroles. They essentially rely on three main types: (1) the multicomponent approach using nitriles or isocyanides, ${ }^{3 \mathrm{~b}, \mathrm{~d}, 8}$ (2) the transition-metal-catalyzed cycloisomerization of alkynes and allenes, ${ }^{3 c, 9}$ and (3) miscellaneous domino (cascade) approaches. ${ }^{10}$
Over the last years, our group has been focused on the design and development of domino processes based on the propargyl Claisen rearrangement of propargyl enol ethers (PVEs). ${ }^{11}$ In a previous work, ${ }^{12}$ we found that the microwave irradiation of PVEs 1 bearing an electron-withdrawing group (EWG) at the propargylic position led to furans 3 (Scheme 1a). This conversion took place through a domino process

Scheme 1. Strategy for the Domino Synthesis of 2Aminopyrroles
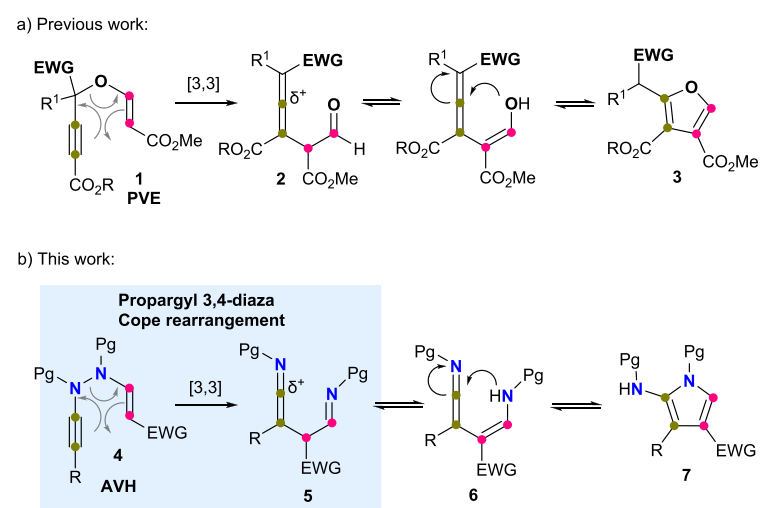

involving the propargyl Claisen rearrangement of $\mathbf{1}$ and the tandem enolization/5-exo-dig O-cyclization of the $\beta$-allenal intermediate 2 . Inspired by this result, we envisioned that this process could be applied toward the preparation of 2aminopyrroles if a convenient $N$-alkynyl, $N^{\prime}$-vinyl hydrazide platform (AVH) such as $\mathbf{4}$ could host the domino reaction

Received: April 20, 2021

Published: April 30, 2021 
(Scheme 1b). The domino reaction should be triggered by the propargylic 3,4-diaza Cope rearrangement of the AVH platform. Surprisingly, there are no precedents in the literature for this sigmatropic rearrangement even though the 3,4-diaza Cope rearrangement of hydrazines is an important reaction in organic synthesis. ${ }^{13}$ The Fischer ${ }^{14 a}$ synthesis of indole and the Piloty $^{14 \mathrm{~b}-\mathrm{d}}$ synthesis of pyrrole constitute iconic examples. We envisioned that the lower BDE of the $\mathrm{N}-\mathrm{N}$ bond $(167 \mathrm{~kJ} /$ mol) compared with the $\mathrm{C}-\mathrm{O}$ bond $(358 \mathrm{~kJ} / \mathrm{mol})$ would reduce the energy barrier for the sigmatropic rearrangement, and in consequence, it could be a feasible process. In addition, we also expected that the electronic configuration of the ethenimine-enamine intermediate 6 should favor the required 5-exo-dig $\mathrm{N}$-cyclization, funneling the whole transformation toward the 2-aminopyrrole 7 . We report herein the results of this study and its implementation as a synthetic strategy to access polysubstituted 2 -aminopyrroles.

In order to test the feasibility of our hypothesis, we first needed to prepare the previously unknown AVHs. Based on our own experience and the well-established synthesis of PVEs from alcohols catalyzed by $\mathrm{DABCO},{ }^{15}$ we envisioned that the incorporation of the vinyl functionality, and thus the synthesis of the AVH platforms from the corresponding $N$-alkynyl hydrazides, ${ }^{16}$ could be realized through the same protocol (Scheme 2). To our delight, the reaction of hydrazides 9 with activated alkynes 10 ( 1.1 equiv) in the presence of catalytic amounts of DABCO (10 mol \%) led to AVHs 4 with an excellent average yield. These conditions were considered satisfactory, and they were not further optimized except for the

Scheme 2. $N$-Alkynyl $N^{\prime}$-Vinyl Hydrazides 4 Used in This Study ${ }^{a}$

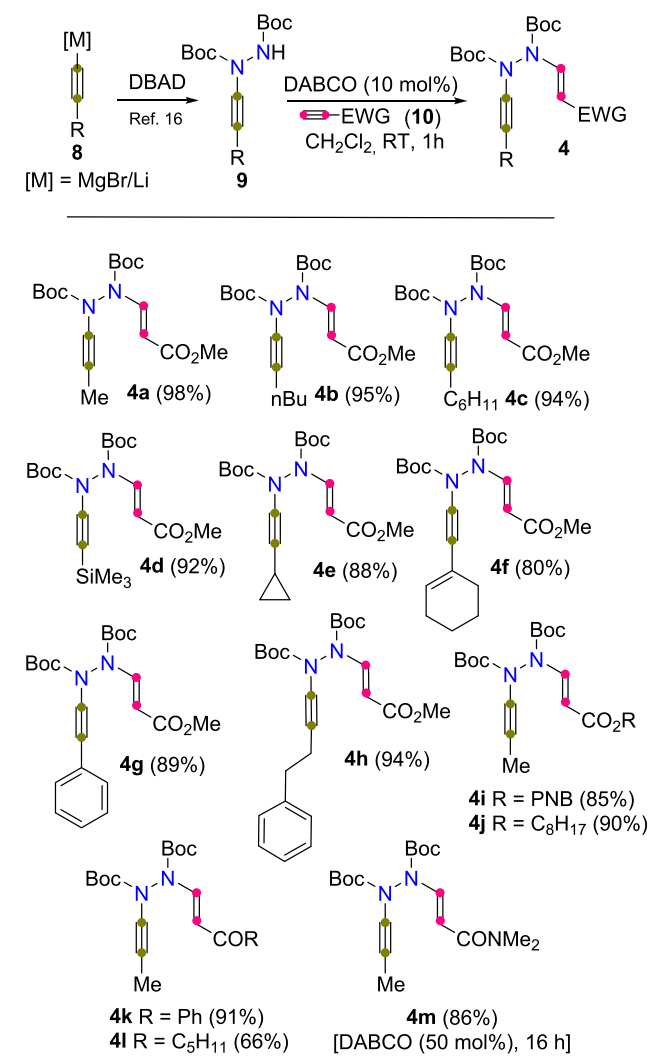

${ }^{a} \mathrm{DBAD}=$ Di-tert-butylazodicarboxylate. $\mathrm{DABCO}=1,4-$ diazabicyclo[2.2.2] octane. PNB = $p$-nitrobenzyl. conjugated amide, which required more time $(16 \mathrm{~h})$ and DABCO (50 mol \%) to deliver the corresponding AVH $4 \mathrm{~m}$ in good yield $(86 \%)$.

Next, we investigated if AVHs 4 could indeed undergo the expected domino transformation triggered by the propargyl 3,4-diaza Cope rearrangement (Scheme 1). AVH 4a was taken as the model platform to study the domino reaction. According to our predictions, heating a solution of $4 a$ in toluene for $24 \mathrm{~h}$ under reflux conditions resulted in the formation of the expected 2 -aminopyrrole $7 \mathbf{a}$ in $17 \%$ yield (Scheme 3 , entry 1 ). To our surprise, we also obtained the 2-aminopyrroles 11a (37\%) and 12a (31\%), which incorporated different $\mathrm{N}$ protection group patterns on their structures. This result suggests that the original protection of both nitrogen atoms is modified along the reaction pathway. A number of experiments were then conducted to study the outcome of the reaction. We first found that the increase of the reaction time from 24 to 72 $\mathrm{h}$ favored the formation of 12a (50\%) over 7a (4\%) and 11a (26\%) (Scheme 3, entry 2). Next, we performed the reaction in refluxing xylenes $(24 \mathrm{~h})$. It was expected that an increase in the reaction temperature should increase the rate of the domino reaction and favor the protecting group translocation (Scheme 3, entry 3). Pleasantly, under these conditions, only the monoprotected 2-aminopyrrole 12a was obtained in an excellent $82 \%$ yield. Furthermore, TLC control showed the sequential appearance and disappearance of products 7 and $\mathbf{1 1}$ and the progressive formation of $\mathbf{1 2}$. It is worthy to note that under these conditions the translocation and elimination of one of the two $\mathrm{N}$-Boc groups along the reaction pathway allow obtaining a single 2-aminopyrrole molecule endowed with an $\mathrm{N}$-Boc-protected 2-amino group and an unsubstituted pyrrole nitrogen, which will be important for further selective synthetic transformations on these molecules and may additionally provide important analogues for SAR studies. The scope of the reaction was studied using the rest of AVH $\mathbf{4 b}-\mathbf{h}$ (Scheme 3, entries 4-20). In general, the reaction manifold tolerated different substituents at the alkyne moiety, including alkyl, cycloalkyl, and aryl groups.

The reaction time required for the whole transformation of 4 into 12 was substituent dependent, spanning from $24 \mathrm{~h}$ for $4 \mathrm{a}$, $4 \mathrm{~b}$, and $4 \mathrm{~g}$ to $72 \mathrm{~h}$ for $4 \mathrm{c}$ (entries $3,7,18$, and 9, respectively). The cyclohexenyl-substituted AVH 4 f could not be selectively transformed into the corresponding monoprotected derivative $12 \mathrm{f}$ (entries 15 and 16). Mixtures of $11 \mathrm{f}$ and $\mathbf{1 2 f}$ were consistently obtained in both toluene and xylenes, although better yields were attained in the first case. Prolonged heating in xylenes afforded decomposition of intermediates and a serious decrease in the yield (entry 16). In the case of the AVH $\mathbf{4 h}$, the replacement of toluene by xylenes decreased the yield of the reaction ( $82 \%$ vs $71 \%$ ), and it could not entirely funnel the reaction toward the derivative $\mathbf{1 2 h}$ (entries 19 and 20). Although mixtures of $11 \mathrm{~h}$ and $12 \mathrm{~h}$ were obtained in both cases, the proportion of $\mathbf{1 2 h}$ increased in xylenes up to $63 \%$ at the expense of a decrease of $11 \mathrm{~h}$ from $21 \%$ to $8 \%$ (entry 21 ). Finally, in the case of AVH $\mathbf{4 d}$, the trimethylsilyl substituent did not tolerate a prolonged reflux in toluene (entry 10) or xylene (entry 11). After $120 \mathrm{~h}$ of heating in toluene under reflux conditions, $4 \mathbf{d}$ afforded a mixture of $\mathbf{1 1 d}(8 \%)$ and $\mathbf{1 2 d}$ (18\%), with complete loss of the silyl group in both structures $(\mathrm{R}=\mathrm{H})$. Under xylene reflux conditions $(18 \mathrm{~h})$, $4 \mathrm{~d}$ provided $12 \mathrm{~d}$ in $29 \%$ yield.

The tolerance of the reaction with regard to the nature of the electron-withdrawing group at the enamine was explored 
Scheme 3. Synthesis of 2-Aminopyrroles 7, 11, and 12 from AVHs 4
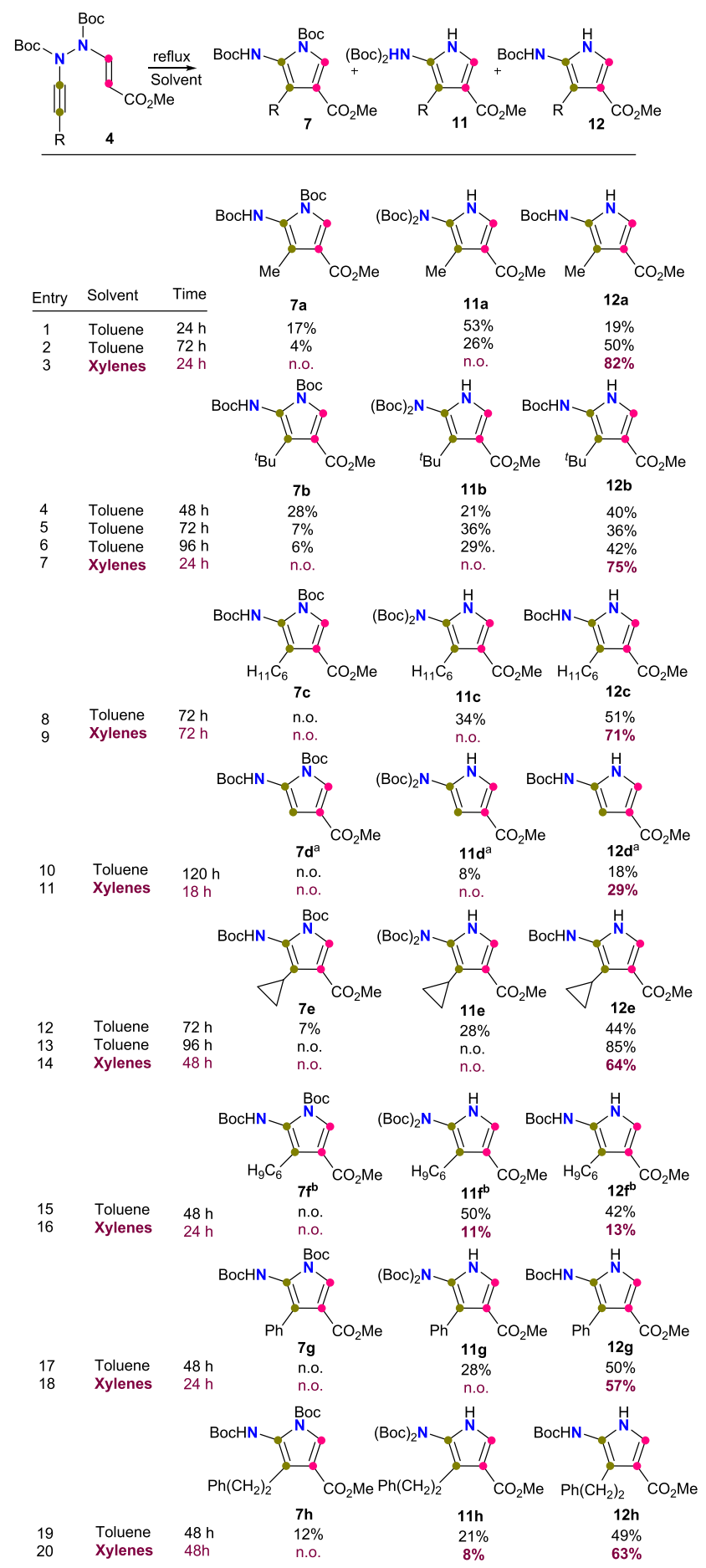

${ }^{a}$ The silyl group of AVH 4d is lost. ${ }^{b}$ Cyclohex-1-en-1-yl. Abbreviations: n.o. $=$ not observed.

with the AVHs $\mathbf{4} \mathbf{i}-\mathbf{m}$, featuring different ester $(\mathbf{4} \mathbf{i}-\mathbf{j})$, ketone $(4 k-1)$, and amide (4m) groups (Scheme 4). All of them delivered the corresponding 2 -aminopyrroles $12 \mathrm{i}-\mathbf{m}$ although with different efficiency. AVHs $\mathbf{4} \mathbf{i}-\mathbf{j}$ armed with an ester group afforded the corresponding 2 -aminopyrroles $12 \mathbf{i}-\mathbf{j}$ in moderate-to-good yields (59\% and $78 \%$, respectively). On the other hand, AVHs endowed with an aliphatic ketone (41) or a tertiary amide group $(\mathbf{4 m})$ gave the corresponding products
Scheme 4. Electron-Withdrawing Group Tolerance ${ }^{a}$
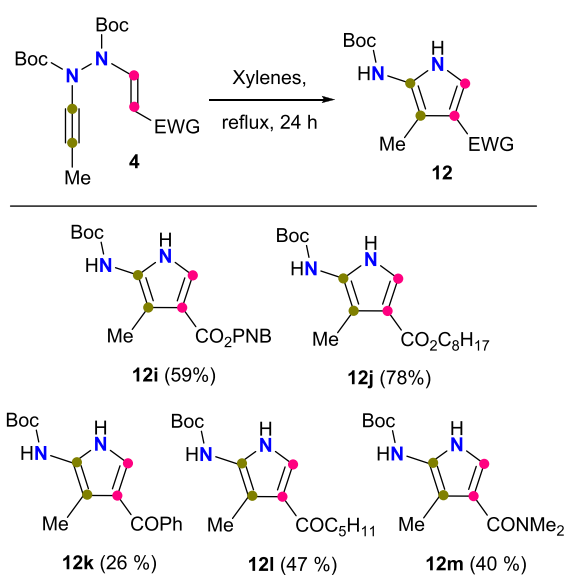

${ }^{a} \mathrm{PNB}=p$-nitrobenzyl.

121 or $12 \mathrm{~m}$ in moderate yields ( $47 \%$ and $40 \%$, respectively). Unfortunately, the efficiency of the reaction manifold was seriously altered when an aromatic ketone was incorporated into the AVH (12k, 26\%).

Overall, these experimental results suggest that a migration/ loss of one of the two N-Boc groups is likely involved in the domino process and that it is temperature dependent (Figure 2 ). To the best of our knowledge, the migration of the BOC

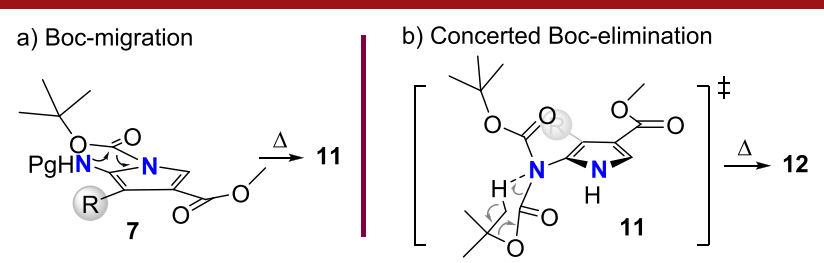

Figure 2. Mechanism of the migration (a) and elimination (b) of the Boc group.

group from the pyrrole nitrogen atom to the exocyclic carbamate nitrogen is unprecedented, and it probably arises from the different chemical reactivity of both nitrogen atoms and their spatial proximity. The experimental results are consistent with the BOC group migration occurring once the sigmatropic rearrangement has been accomplished. The accumulation of derivative $\mathbf{1 1}$ in the reaction medium seems to point out that the elimination process is the energetically most demanding step of the domino process and that it is accomplished at different rates depending on the ring substituent (see Scheme 3, entries 2, 5, 8, and 12).

In summary, we have developed a novel and facile synthetic methodology to access 2-aminopyrroles from previously unknown but easily accessible $N$-alkynyl, $N^{\prime}$-vinyl hydrazides through an unprecedented 3,4-diaza Cope rearrangement and a 5-exo-dig $\mathrm{N}$-cyclization reaction. Using this strategy, we built a small library of 29 different 2-aminopyrroles with diverse protection patterns. The whole domino process can be harnessed to selectively deliver a single 2 -aminopyrrole with the amine nitrogen protected as its $N$-Boc and the pyrrole nitrogen free $(\mathrm{N}-\mathrm{H})$. This result highlights the symmetrybreaking power of this manifold, which transforms a linear and symmetrically protected hydrazide platform into an asymmetrically protected 2 -aminopyrrole molecule. 


\section{ASSOCIATED CONTENT}

\section{SI Supporting Information}

The Supporting Information is available free of charge at https://pubs.acs.org/doi/10.1021/acs.orglett.1c01345.

Experimental procedures and spectral data for all new compounds 4, 7, 9, 11, and 12 (PDF)

\section{AUTHOR INFORMATION}

\section{Corresponding Authors}

Fernando García Tellado - Instituto de Productos Naturales y Agrobiología, CSIC, 38206 La Laguna, Tenerife, Spain; ○ orcid.org/0000-0001-6470-6289; Email: fgarcia@ ipna.csic.es

David Tejedor - Instituto de Productos Naturales y Agrobiología, CSIC, 38206 La Laguna, Tenerife, Spain; Email: dtejedor@ipna.csic.es

\section{Authors}

Raquel Diana-Rivero - Instituto de Productos Naturales y Agrobiología, CSIC, 38206 La Laguna, Tenerife, Spain; Doctoral and Postgraduate School, Universidad de La Laguna, Santa Cruz de Tenerife, Spain

Beate Halsvik - Department of Chemistry, University of Bergen, NO-5007 Bergen, Norway

Complete contact information is available at: https://pubs.acs.org/10.1021/acs.orglett.1c01345

\section{Author Contributions}

The manuscript was written through contributions of all authors. All authors have given approval to the final version of the manuscript.

\section{Author Contributions}

"Contributed to the work at IPNA-CSIC during a research visit.

Notes

The authors declare no competing financial interest.

\section{ACKNOWLEDGMENTS}

This research was supported by the Spanish Ministries of Science, Innovation and Universities (MICINN), Agencia Estatal de Investigación (AEI) and the European Regional Development Funds (ERDF) (PGC2018-094503-B-C21). The research stay for Beate Halsvik at IPNA-CSIC was made possible by a travel grant from the Norwegian $\mathrm{PhD}$ School of Pharmacy.

\section{REFERENCES}

(1) (a) Wallace, M.; Adams, M.; Kanouni, T.; Mol, C.; Dougan, D.; Feher, V.; O'Connell, S.; Shi, L.; Halkowycz, P.; Dong, Q. Structurebased design and synthesis of pyrrole derivatives as MEK inhibitors. Bioorg. Med. Chem. Lett. 2010, 20, 4156. (b) McGeary, R.; Tan, D.; Selleck, C.; Pedroso, M. M.; Sidjabat, H.; Schenk, G. Structure-based design and synthesis of pyrrole derivatives as MEK inhibitors. Eur. J. Med. Chem. 2017, 137, 351. (c) Li Petri, G.; Spano, V.; Spatola, R.; Holl, R.; Raimondi, M. V.; Barraja, P.; Montalbano, A. Bioactive pyrrole-based compounds with target selectivity. Eur. J. Med. Chem. 2020, 208, 112783.

(2) (a) Sajadikhah, S. S.; Zare, A. Synthesis of pyrrolo[2,3d]pyrimidines. Chem. Heterocycl. Compd. 2019, 55, 1168. (b) De Coen, L. M.; Heugebaert, T. S. A.; García, D.; Stevens, C. V. Synthetic entries to and biological activity of pyrrolopyrimidines. Chem. Rev.
2016, 116, 80. (c) Mohamed, M. S.; Kamel, R.; Fatahala, S. S. New condensed pyrroles of potential biological interest. Syntheses and structure-activity relationship studies. Eur. J. Med. Chem. 2011, 46, 3022.

(3) For selected reviews of synthesis of pyrroles including 2aminopyrroles, see: (a) Neto, J. S. S.; Zeni, G. Transition metalcatalyzed and metal-free cyclization reactions of alkynes with nitrogen-containing substrates: synthesis of pyrrole derivatives. ChemCatChem 2020, 12, 3335. (b) Estévez, V.; Villacampa, M.; Menéndez, J. C. Recent advances in the synthesis of pyrroles by multicomponent reactions. Chem. Soc. Rev. 2014, 43, 4633. (c) Gulevich, A. V.; Dudnik, A. S.; Chernyak, N.; Gevorgyan, V. Transition metal-mediated synthesis of monocyclic aromatic heterocycles. Chem. Rev. 2013, 113, 3084. (d) Estévez, V.; Villacampa, M.; Menéndez, J. C. Multicomponent reactions for the synthesis of pyrroles. Chem. Soc. Rev. 2010, 39, 4402.

(4) Knorr, L. Synthese von pyrrolderivaten. Ber. Dtsch. Chem. Ges. 1884, 17, 1635.

(5) Paal, C. Synthese von thiophen- und pyrrolderivaten. Ber. Dtsch. Chem. Ges. 1885, 18, 367.

(6) Hantzsch, A. Neue bildungsweise von pyrrolderivaten. Ber. Dtsch. Chem. Ges. 1890, 23, 1474.

(7) For a recent review, see: Xuan, D. D. Recent progress in the synthesis of pyrroles. Curr. Org. Chem. 2020, 24, 622.

(8) For selected examples, see: (a) Wang, X.; Xu, X.; Wang, S.; Zhou, W.; Ji, S. Highly efficient chemoselective synthesis of polysubstituted pyrroles via isocyanide-based multicomponent domino reaction. Org. Lett. 2013, 15, 4246. (b) Frolova, L. V.; Evdokimov, N. M.; Hayden, K.; Malik, I. 1.; Rogelj, S.; Kornienko, A. I.; Magedov, V. One-pot multicomponent synthesis of diversely substituted 2aminopyrroles. A short general synthesis of rigidins A, B, C, and D. Org. Lett. 2011, 13, 1118. (c) Kolontsova, A. N.; Ivantsova, M. N.; Tokareva, M. I.; Mironov, M. A. Multicomponent interphase synthesis of heterocyclic compounds. Mol. Diversity 2010, 14, 543. (d) Wang, K.; Dömling, A. Design of a versatile multicomponent reaction leading to 2-amino-5-ketoaryl pyrroles. Chem. Biol. Drug Des. 2010, 75, 277.

(9) For selected reviews, see: (a) Hong, F.-L.; Ye, L.-W. Transition metal-catalyzed tandem reactions of ynamides for divergent $\mathrm{N}$ heterocycle synthesis. Acc. Chem. Res. 2020, 53, 2003. (b) Li, L.; Tan, T.-D.; Zhang, Y.-Q.; Liu, X.; Ye, L.-W. Recent advances in transitionmetal-catalyzed reactions of alkynes with isoxazoles. Org. Biomol. Chem. 2017, 15, 8483. For selected examples, see: (c) Funt, L. D.; Krivolapova, Y. V.; Khoroshilova, O. V.; Novikov, M. S.; Khlebnikov, A. F. 2H-Azirine-2-carbonyl azides: preparation and use as $\mathrm{N}$ heterocyclic building blocks. J. Org. Chem. 2020, 85, 4182. (d) Galenko, E. E.; Linnik, S. A.; Khoroshilova, O. V.; Novikov, M. S.; Khlebnikov, A. F. Isoxazole strategy for the synthesis of $\alpha$ aminopyrrole derivatives. J. Org. Chem. 2019, 84, 11275. (e) Cao, Z.; Zhu, J.; Liu, L.; Pang, Y.; Tian, L.; Sun, X.; Meng, X. AgNTf2catalyzed formal $[3+2]$ cycloaddition of ynamides with unprotected isoxazol-5-amines: efficient access to functionalized 5-amino- $1 \mathrm{H}$ pyrrole-3-carboxamide derivatives. Beilstein J. Org. Chem. 2019, 15, 2623. (f) Wu, Y.; Zhu, L.; Yu, Y.; Luo, X.; Huang, X. Polysubstituted 2 -aminopyrrole synthesis via gold-catalyzed intermolecular nitrene transfer from vinyl azide to ynamide: reaction scope and mechanistic insights. J. Org. Chem. 2015, 80, 11407. (g) Zhu, L.; Yu, Y.; Mao, Z.; Huang, X. Gold-catalyzed intermolecular nitrene transfer from $2 \mathrm{H}$ azirines to ynamides: a direct approach to polysubstituted pyrroles. Org. Lett. 2015, 17, 30. (h) Wang, S.; Ni, Z.; Huang, X.; Wang, J.; Pan, Y. Copper-catalyzed direct amidation of heterocycles with $\mathrm{n}$ fluorobenzenesulfonimide. Org. Lett. 2014, 16, 5648. (i) Kramer, S.; Madsen, J. L. H.; Rottlander, M.; Skrydstrup, T. Access to 2,5diamidopyrroles and 2,5-diamidofurans by AU(I)-catalyzed double hydroamination or hydration of 1,3-diynes. Org. Lett. 2010, 12, 2758. (j) Demir, A. S.; Emrullahoglu, M.; Buran, K. Gold(I)/Zn(II) catalyzed tandem hydroamination/annulation reaction of 4-ynenitriles. Chem. Commun. 2010, 46, 8032. 
(10) For selected examples, see: (a) Liu, J.; Li, Q.; Cao, Z.-M.; Jin, Y.; Lin, J.; Yan, S.-J. Cascade reaction of Morita-Baylis-Hillman acetates with 1,1-enediamines or heterocyclic ketene aminals: synthesis of highly functionalized 2-aminopyrroles. J. Org. Chem. 2019, 84, 1797. (b) Guchhait, S. K.; Sisodiya, S.; Saini, M.; Shah, Y. V.; Kumar, G.; Daniel, D. P.; Hura, N.; Chaudhary, V. Synthesis of polyfunctionalized pyrroles via a tandem reaction of Michael addition and intramolecular cyanide-mediated nitrile-to-nitrile condensation. $J$. Org. Chem. 2018, 83, 5807. (c) Reekie, T. A.; Donckele, E. J.; Manenti, G.; Püntener, S.; Trapp, N.; Diederich, F. A three-step synthesis of tetrasubstituted NH-pyrroles. Org. Lett. 2016, 18, 2252. (d) Qi, X.; Xiang, H.; He, Q.; Yang, C. Synthesis of multisubstituted 2-aminopyrroles/pyridines via chemoselective Michael addition/ intramolecular cyclization reaction. Org. Lett. 2014, 16, 4186. (e) Demir, A. S.; Emrullahoglu, M. Zinc perchlorate catalyzed onepot amination-annulations of a-cyanomethyl- $\beta$-ketoesters in water. Regioselective synthesis of 2-aminopyrrole-4-carboxylates. Tetrahedron 2006, 62, 1452. (f) Chien, T.-C.; Meade, E. A.; Hinkley, J. M.; Townsend, L. B. Facile synthesis of 1-substituted 2-amino-3cyanopyrroles: new synthetic precursors for 5,6-unsubstituted pyrrolo[2,3-d]pyrimidines. Org. Lett. 2004, 6, 2857.

(11) (a) Tejedor, D.; Delgado-Hernández, S.; Santamaría-Peláez, B.; García-Tellado, F. Short and modular synthesis of tetraarylsalicylaldehydes. Chem. Commun. 2020, 56, 4019. (b) Tejedor, D.; DíazDíaz, A.; Diana-Rivero, R.; Delgado-Hernández, S.; García-Tellado, F. Synthesis and utility of 2,2-dimethyl-2H-pyrans: dienes for sequential Diels-Alder/retro-Diels-Alder reactions. Org. Lett. 2018, 20, 7987. (c) Tejedor, D.; Delgado-Hernández, S.; Peyrac, J.; González-Platas, J.; García-Tellado, F. Integrative pericyclic cascade: an atom economic, multi $\mathrm{C}-\mathrm{C}$ bond-forming strategy for the construction of molecular complexity. Chem. - Eur. J. 2017, 23, 10048. (d) Tejedor, D.; López-Tosco, S.; Méndez-Abt, G.; Cotos, L.; García-Tellado, F. Propargyl vinyl ethers and tertiary skipped diynes: two pluripotent molecular platforms for diversity-oriented synthesis. Acc. Chem. Res. 2016, 49, 703. (e) Tejedor, D.; Cotos, L.; Márquez-Arce, D.; Odriozola-Gimeno, M.; Torrent-Sucarrat, M.; Cossío, F. P.; GarcíaTellado, F. Microwave-assisted organocatalyzed rearrangement of propargyl vinyl ethers to salicylaldehyde derivatives: an experimental and theoretical study. Chem. - Eur. J. 2015, 21, 18280. (f) Tejedor, D.; Méndez-Abt, G.; Cotos, L.; García-Tellado, F. Merging domino and redox chemistry: stereoselective access to di- and trisubstituted $\beta, \gamma$ unsaturated acids and esters. Chem. - Eur. J. 2012, 18, 3468.

(12) Tejedor, D.; Cotos, L.; García-Tellado, F. Microwave-assisted domino access to $\mathrm{C}_{2}$-chain functionalized furans from tertiary propargyl vinyl ethers. Org. Lett. 2011, 13, 4422.

(13) (a) Endo, Y.; Shudo, K. Anionic 3,4-diaza-3.3,sigmatropic rearrangements of $N, N^{\prime}$-diacylhydrazines. Tetrahedron Lett. 1991, 32, 4517. (b) Sucrow, W.; Bethke, H.; Chondromatidis, G. Thermolyse von 1.2.4.5-tetramethyl-hexahydro-1.2.4.5-tetrazinen im massenspektrometer. Tetrahedron Lett. 1971, 12, 1481. (c) Sucrow, W.; Chondromatidis, G. Symmetrische $N$-methyl-pyrrole iiber enhydrazine. Chem. Ber. 1970, 103, 1759.

(14) (a) Humphrey, G. R.; Kuethe, J. T. Practical methodologies for the synthesis of indoles. Chem. Rev. 2006, 106, 2875. (b) Piloty, O. Synthese von Pyrrolderivaten: Pyrrole aus Succinylobernsteinsäureester, Pyrrole aus Azinen. Ber. Dtsch. Chem. Ges. 1910, 43, 489. For selected examples, see: (c) Milgram, B. C.; Eskildsen, K.; Richter, S. M.; Scheidt, W. R.; Scheidt, K. A. Microwave-assisted Piloty-Robinson synthesis of 3,4-disubstituted pyrroles. J. Org. Chem. 2007, 72, 3941. and references cited therein. (d) Rivero, R. M.; Buchwald, S. L. Copper-catalyzed vinylation of hydrazides. A regioselective entry to highly substituted Pyrroles. Org. Lett. 2007, 9, 973.

(15) Tejedor, D.; Alvarez-Méndez, S. J.; López-Soria, J. M.; Martín, V. S.; García-Tellado, F. A robust and general protocol for the Lewisbase-catalysed reaction of alcohols and alkyl propiolates. Eur. J. Org. Chem. 2014, 2014, 198.

(16) N-Alkynyl hydrazides $\mathbf{8 b}-\mathbf{g}$ were synthesized using the reported procedure by Batey and col.: Beveridge, R.; Batey, R. Terminal alkyne addition to diazodicarboxylates: synthesis of hydrazide linked alkynes (ynehydrazides). Org. Lett. 2012, 14, 540. $\mathrm{N}$-Alkynyl hydrazides $\mathbf{8 a}$ and $\mathbf{8 h}$ were synthesized following a modified version of this protocol (see SI). 